Nazar Gh Jameel BDS, MSc (Assist Prof)

Nawfal A Zakaria BDS, MSc (Lect)

\section{Radiological accuracy in the interpretation of apical fitness in endodontics}

\author{
Department of Oral and Maxillofacial Surgery \\ College of Dentistry, University of Mosul \\ Department of Conservative Dentistry \\ College of Dentistry, University of Mosul
}

\begin{abstract}
Aim: To compare the accuracy of right-angle paralleling and bisecting-angle radiographic techniques in the determination of apical fitness in endodontic therapy. Materials and Methods: Thirty three root canals of first upper and lower molar teeth have been used in this study. A K-file was inserted into the canal until its tip was fit snuggly one millimeter shorter than the apex. Each tooth then radiographed twice by the right-angle paralleling and bisecting-angle techniques. The distance between the file tip and the center of radiographical apex was directly measured by two examiners and the mean of each two measurements was recorded. Data were collected and analyzed statistically by analysis of variance and Duncan's Multiple Range test. Results: The mean value revealed that there were clear differences between the mean of measurements by the parallel technique $(0.87 \mathrm{~mm})$ and that with the bisecting technique $(0.39 \mathrm{~mm})$, when these two results compared with the mean of real measurements $(1 \mathrm{~mm})$. One way analysis of variance revealed there were significant differences in one of the three groups at $p \leq 0.05$ level. Duncan' Multiple Range test showed that the parallel measurements when compared with the real measurements the results showed that there was no significant difference but was significantly different from the bisecting measurements. Conclusion: It is preferable to the dentist to use the right-angle paralleling technique during root canal treatment, where it gives more accurate result for estimation of the working length. Key Words: Parallel, bisecting, apical fitness.
\end{abstract}

Jameel NGh, Zakaria NA. Radiological accuracy in the interpretation of apical fitness in endodontics. Al-Rafidain Dent J. 2006; 6(2): 151-154.

Received: 30/10/2005 Sent to Referees: 2/11/2005 Accepted for Publication: 5/1/2006

\section{INTRODUCTION}

Radiographs are essential to all phases of endodontic therapy. They inform the diagnosis and the various treatment phases and help to evaluate the success or failure of treatment. ${ }^{(1)}$ Successful root canal therapy depends upon complete and accurate biomechanical preparation followed by a three-dimensional obturation of the root canal system without injuring the periapical tissue. To attain these objectives, the endpoint of the root canal system should be detected carefully prior to preparation of the canal. The ideal apical endpoint of a root canal is considered to be the apical constriction or cementodentinal junction of a tooth with completed root formation. ${ }^{(2)}$ In the 1920's, Blaney and Coolidge offered information indicated that filling slightly short of the root tip give the best results. ${ }^{(2)}$ Accuracy in length determination is necessary to avoid damage to the apices of teeth and to the periapical tissues during instrumentation, thus providing better conditions for healing after endodontic treatment. ${ }^{(3)}$ The general acceptable method for working length determination is to take periapical radiographs with an instrument placed in the root canal. ${ }^{(4)}$ Radiography is the most reliable of all the diagnostic tests and provides the most valuable information. In all endodontic cases, a good intra-oral parallel radiograph of the root and periapical region is mandatory. ${ }^{(5)}$

Although most of dentists use the bisecting angle technique for the determination of the working length because it is 
easier, but it may give false information about accurate working length due to the distortion, but the parallel technique is recommended over the bisecting technique because it shows less distortion and minimal enlargement which makes it indicated for root canal treatment. ${ }^{(6)}$

The purpose of this study was to evaluate the accuracy of two radiographic techniques; i.e., the right-angle paralleling and bisecting-angle in the determination of apical fitness in endodontics.

\section{MATERIALS AND METHODS}

Fourteen extracted multi-rooted (upper and lower) first molar teeth have been used in this study. The selected teeth were placed in the normal saline after extraction, and then examined clinically to satisfy the following criteria:

1. The crown was completely formed; i.e., free from the extensive carious lesion.

2. The root(s) was (were) without extensive curvature and abnormal anatomy.

3. The apical foramen was completely formed.

4. The canal of examined root was free from any blockage, and internal or apical resorption.

Each root of the tooth not satisfies these criteria was excluded (Figure 1). Scaling was done by ultrasonic scalar to remove calculus and stains. The total number of the roots were 33 after excluding some of them according to the above criteria.

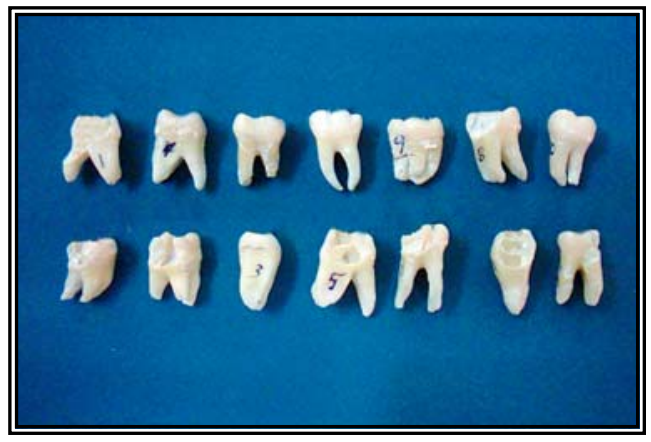

Figure (1): The samples of 14 extracted upper and lower molar teeth

After access preparation, a K-file was inserted into the canal until the tip of the file was just seen at the main apical foramen. The file then was withdrown one millimeter shorter than the apex. Initial instrumentation was performed two sizes larger than the first file that fit snuggly within one millimeter of the apex. The file was fixed in the canal by filling the access with composite resin. ${ }^{(5)}$

Each tooth was then radiographed twice.

The first radiograph was taken by the right-angle paralleling technique with the use of wooden film holder to facilitate the positioning of the examined tooth (Figure 2); where the second radiograph was taken by the bisecting-angle technique. A cotton role was inserted between the root of the tooth and the film to initiate an angle between the long axis of the tooth and the plane of the film according the geometric principles of bisecting-angle technique (Figure 3). All the samples were positioned during radiography in relation with the film as in the human jaws.

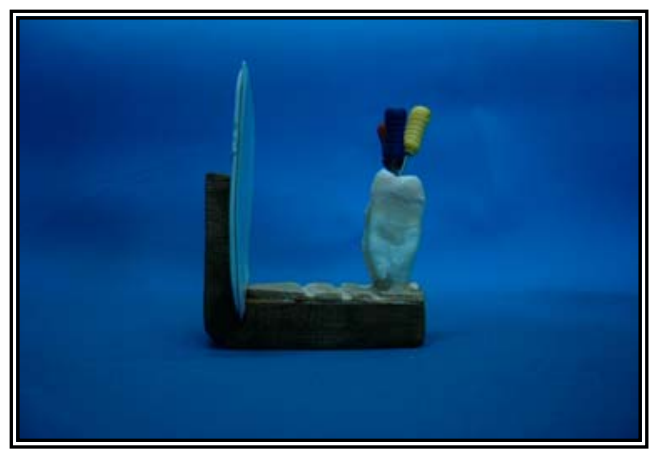

Figure (2): Position of the tooth in the right-angle paralleling technique

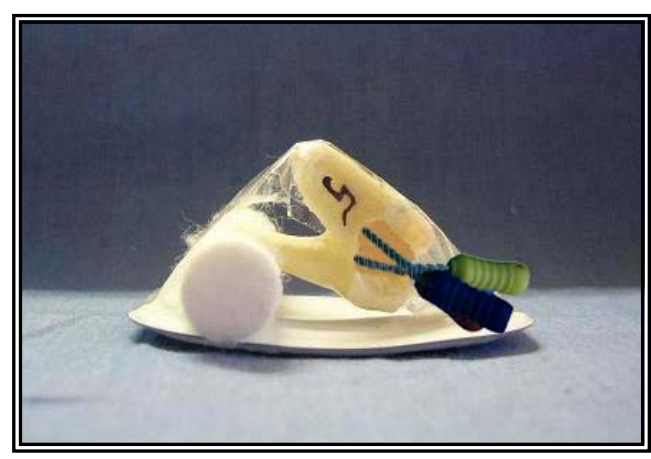

Figure (3): Position of the tooth in the bisecting-angle technique

The radiographic machine of type TROPHY MINOREX (made in France) was adjusted on $65 \mathrm{kVp}, 10 \mathrm{~mA}$ and 0.5 second of exposure time and size-2, Espeed film (Kodak Poly-soft, by Eastman Kodak company, USA) was used. After 
processing, each radiograph viewed and examined under magnifying lens. The distance between the file tip and the center of radiographic apex was directly measured by two examiners using divider and vernier of $0.05 \mathrm{~mm}$ error, and the mean of each two measurements was taken.

The data were collected and analyzed statistically by analysis of variance (ANOVA) and Duncan's Multiple Range test.

\section{RESULTS AND DISCUSSION}

The results of mean value revealed that there were clear differences between the mean of measurements by the parallel technique $(0.87 \mathrm{~mm})$ and that with the bisecting technique $(0.39 \mathrm{~mm})$, when these two results compared with the mean of real measurements $(1 \mathrm{~mm})$. The mean of parallel technique was very near to the real one. This is due to the accuracy of this technique and minimal distortion and enlargement, also review approximately the same length of the tooth to be treated endodontically. ${ }^{(7)}$

While when comparing the mean of measurements by the bisecting technique with the real measurements, the result showed greater differences than that with parallel technique. This is due to the distortion which my occur because the geometric principles of bisecting-angle technique makes unequal distance between the film and the tooth along the total length of the tooth. ${ }^{(6)}$

One way ANOVA revealed that there were significant differences in one of the three groups at $\mathrm{p} \leq 0.05$ level (Table 1).

Table (1): Analysis of variance for the different techniques

\begin{tabular}{cccccc}
\hline Source & df & SS & MS & F-value & $\boldsymbol{p}$-value \\
\hline Factor & 2 & 6.6681 & 3.3340 & \multirow{2}{*}{55.61} & 0.000 \\
Error & 96 & 5.7552 & 0.0599 & & \\
\cline { 1 - 3 } Total & 98 & 12.4232 & & & \\
\cline { 1 - 3 }
\end{tabular}

SS: Sum of Squares; MS: Mean square; df: Degree of freedom.

Duncan's Multiple Range test (Table 2) showed that the parallel measurements were significantly different from the bisecting measurements, but when compared with the real measurements, the results showed that there was no significant diff- erence due to geometrically accurate images that produced with little magnification and the periapical tissues are accurately shown with minimal shortening or elongation. ${ }^{(8,9)}$

Table (2): Duncan's Multiple Range test for the different techniques

\begin{tabular}{cccc}
\hline Group & No. & Mean \pm SD & $\begin{array}{c}\text { Duncan's } \\
\text { Group* }\end{array}$ \\
\hline Bisecting Angle & 33 & $0.3970 \pm 0.3566$ & $\mathrm{~A}$ \\
Parallel Technique & 33 & $0.8727 \pm 0.2295$ & $\mathrm{~B}$ \\
Real Length (Control) & 33 & $1.000 \pm 0.000$ & $\mathrm{~B}$ \\
\hline *Means with the same letter were statistically not significant $(p>0.05)$
\end{tabular}

While comparison of the bisecting group with both parallel and real showed that the bisecting technique was significantly differ from the parallel and real techniques. Many variables involved in the technique often result in the image being badly distorted. Incorrect vertical angulation will result in foreshortening or elong- ation of the image ${ }^{(10)}$. The results gained from the present study coincided with the previous studies performed by Langland and Sippy ${ }^{(11)}$ and Vande Voorde et al. ${ }^{(12)}$ They concluded that the paralleling technique is a reliable radiographic technique for working length determination in an endodontics. In contrary with the studies 
made by Al-Dulaime and Dawood ${ }^{(13)}$ and Kakka, ${ }^{(6)}$ who found that the bisectingangle technique is more accurate in working length determination in an endodontic treatment.

\section{CONCLUSION}

It is preferable to the dentist to use the right-angle paralleling technique during root canal treatment, where it gives more accurate result for estimation of the working length.

\section{REFERENSES}

1. Cohen S. Pathways of the Pulp. $7^{\text {th }}$ ed. CV Mosby Co. St Louis. 1998; p: 89.

2. Nekoofar MH, Sadeghi K, Sadighi Akha E, Sadegh Namazikhah M. The accuracy of the Neosono Ultima EZ apex locator using files of different alloys: An in vitro study. J Calif Dent Assoc. 2002; 28(2): 320-326.

3. Cox VS, Brown CE, Bricker SL, Newton CW. Radiographic interpretation of endodontic file length. Oral Surg Oral Med Oral Pathol. 1991; 72(3): 340-344.

4. Benkel HD, Formmer H, Rosenbery PA, Stieglitz HT. Comparison of endodontics measurement controls using a paralleling technique with a grid and a conventional measurement. Oral Surg. 1980; 49: 157-161.

5. Carrotte P. Endodontics- Part 2: Diagnosis and treatment planning. $\mathrm{Br}$ Dent
J. 2004; 197: 231-238.

6. Kakka LN. Determination of the working length in root canal treatment using bisecting angle technique. Al-Mustansiria Dent J. 2004; 1(2): 139-144.

7. Bernice M, Jin J, Qiang Z. Measurement of the distance between the minor foramen and the anatomic apex by digital and conventional radiography. J Endod. 2002; 28(2): 125-126.

8. Edward B, Michanowicz AE, Michanowicz JP. Practical Endodontics. 1994; Pp: 41-56.

9. Goaz PW, White SC. Oral Radiology: Principles and Interpretation. $3^{\text {rd }}$ ed. CV Mosby Co. St Louis. 1994.

10. Forsberg J. A comparison of the parallel and bisecting-angle radiographic technique in endodontics. Int Endod J. 1987; 177-182.

11. Langland OE, Sippy FH. Study of radiographic longitudinal distortion of anterior teeth using the paralleling technique. Oral Surg. 1966; 22(8): 737-748.

12. Vande Voorde HE, Moline D, Bjornadahl AM. Estimating endodontic working length with paralleling radiographs. Oral Surg. 1969; 27(1): 106-110.

13. Al-Dulaime FN, Dawood FF. A comparison between uniform and irregular objects image dimensional distortion in both bisecting-angle and parallel techniques. MSc thesis. College of Dentistry. University of Baghdad. 1990. 